\title{
Acute Intermittent Porphyria: A Diagnostic Challenge
}

\author{
Rahim Vakili, ${ }^{1, *}$ and Parisa Armanpoor ${ }^{1}$ \\ ${ }^{1}$ Department of Pediatric Endocrinology and Metabolism, School of Medicine, Mashhad University of Medical Sciences, Mashhad, IR Iran \\ "Corresponding author: Rahim Vakili, Department of pediatric Endocrinology and Metabolism, School of Medicine, Mashhad University of Medical Sciences, Mashhad, IR Iran. \\ Tel: +98-9151145830. E-mail: vakilir@mums.ac.ir
}

Received 2016 January 22; Revised 2016 January 26; Accepted 2016 February 18.

Keywords: Acute Intermittent Porphyria, Anti-Epileptic Drugs, Epilepsy

\section{Dear Editor,}

Porphyrias refer to a group of rare inherited metabolic disorders resulting from reduced activity of any of the enzymes in the heme production pathway. Accumulation of the porphyrin precursors is associated with diverse pathologic changes, and become the basis for diagnostic tests (1). Acute intermittent porphyria (AIP) is the most common type of porphyrias, and seizures are typically a manifestation of acute attacks. AIP can also be associated with idiopathic or symptomatic epilepsy (2). Since many antiepileptic drugs can worsen the patient's condition or disease attacks, knowledge of the effects of AEDs is important. Trying to treat seizures may unmask AIP, which has been previously hidden. Due to the broad spectrum of clinical symptoms, porphyry diagnosis depends on a strong clinical suspicion (3). We present here a child with the final diagnosis of porphyria.

A 7-year-old boy was born at term of healthy, consanguineous Iranian parents. In the first week of life, he started with myoclonic seizures and admitted into the NICU. Physical exam and other investigations such as brain imaging and lab data were normal. The patient remained asymptomatic and medications gradually discontinued. At age five, the patient had tonic colonic seizures and referred to pediatric neurologist. The EEG demonstrated epileptic waves and brain MRI was normal. He was prescribed phenobarbital as the first medication. He did not show any improvement; instead, his condition deteriorated after anti-epileptic treatments, because of which his medicines were discontinued. He had consulted many physicians and went to several centers for 2 years. Furthermore, he was referred to department of pediatric endocrinology and metabolism seeking metabolic consultation for convulsion. This time, detailed history was taken. In addition to seizures, the parents complained of his chronic periodic abdominal pain and headaches. By this history, porphyria was clinically the most suspi- cious entity. A 24-hour-urine sample was collected and sent for quantitative measurements (high performance liquid chromatography (HPLC)). The urine sample was highly positive for porphyrin metabolites such as coproporphyrin and pentacarboxyporphyrin. The marked elevation in porphyrin metabolites confirmed diagnosis of an acute porphyria, the most common of which is acute intermittent porphyria. Confirmation of the type of acute porphyria requires additional biochemical and genetic testing considered for the next follow up.

Four of the porphyrias cause acute neurological syndromes, which categorize into both neuroporphyrias (acute intermittent porphyria and plumboporphyria) and neurocutaneous porphyrias (hereditary coproporphyria and variegate porphyria)(4). Acute intermittent porphyria (AIP) is the most frequent of the four forms of neuroporphyrias (4). Symptoms of the disease in the same patient during different episodes and in patients with the same porphyria subtype are different. Disease attacks may be similar to some other psychiatric or medical disorders, which increases the risk of error in the decision (1).

AIP is a rare autosomal dominant metabolic disorder, and results from a deficiency of the enzyme porphobilinogen deaminase. Almost 90\% of those who inherit this disorder remain asymptomatic throughout their lives (3). During acute attacks, the urine may be found to contain PBG, porphyrins and the precursor of PBG, aminoflavulinic acid (ALA) (5). The most common method for separating the individual porphyrins is HPLC (4). This method will identify amounts of urine porphyrins with four or more carboxyl groups. AIP is usually asymptomatic before puberty and is more common in females than males. Symptoms may be intensified by hormonal and nutritional factors and by prescripting some drugs especially most AEDs (3). Abdominal pain is almost always associated with attacks in AIP (1).

Cases of AIP in childhood have continued to be reported at intervals (3), though it may be that the use of

Copyright (c) 2016, Growth \& Development Research Center. This is an open-access article distributed under the terms of the Creative Commons Attribution-NonCommercial 4.0 International License (http://creativecommons.org/licenses/by-nc/4.0/) which permits copy and redistribute the material just in noncommercial usages, provided the original work is properly cited. 
diazepam, which is safe, instead of phenobarbital, for the emergency treatment of seizures, has resulted in fewer instances of children with latent AIP developing symptoms of the disease (3).

Genetic testing helps to differentiate types of porphyry, but unfortunately is not available in many centers (6). Currently, the Mount Sinai genetic testing laboratory in New York city is the only laboratory offering expensive DNA testing for types of porphyrias (5). Unfortunately, our patient declined to perform genetic testing.

This case shows the variable presentation of AIP and emphasizes the importance of considering the diagnosis even in young patients with neurologic conditions associated with nonspecific neurovisceral symptoms or unexplained intensified neurologic symptoms.

\section{References}

1. Gonzalez-Arriaza HL, Bostwick JM. Acute porphyrias: a case report and review. Am J Psychiatry. 2003;160(3):450-9. doi: 10.1176/appi.ajp.160.3.450. [PubMed: 12611823].

2. Walker KL, Lipori P, Lee WA, Beaver TM. Cost of thoracic endovascular aortic repair versus open repair and implications for the US health care system. J Thorac Cardiovasc Surg. 2010;139(1):231-2. doi: 10.1016/j.jtcvs.2009.07.020. [PubMed: 19691999].

3. Sykes RM. Acute intermittent porphyria, seizures, and antiepileptic drugs: a report on a 3-year-old Nigerian boy. Seizure. 2001;10(1):64-6. doi: 10.1053/seiz.2000.0473. [PubMed: 11181101].

4. Deacon HA, Peters T. Diagnosis and management of porphyria. Br Med J. 2000;320:1647-51. doi:10.1136/bmj.320.7250.1647.

5. American Porphyria Foundation. Testing for Porphyria 2015. Available from: http://www.porphyriafoundation.com/testing-for-porphyria.

6. Trier H, Krishnasamy VP, Kasi PM. Clinical manifestations and diagnostic challenges in acute porphyrias. Case Rep Hematol. 2013;2013:628602. doi: 10.1155/2013/628602. [PubMed: 23476835]. 